\title{
Patterns and principles for blended synchronous learning: Engaging remote and face-to-face learners in rich-media real-time collaborative activities
}

\author{
Matt Bower, Jacqueline Kenney \\ Macquarie University, Australia \\ Barney Dalgarno, Mark J. W. Lee \\ Charles Sturt University, Australia \\ Gregor E. Kennedy \\ The University of Melbourne, Australia
}

\section{Best Full Paper Award recipient, ascilite Sydney 2013 Conference}

\begin{abstract}
Blended synchronous learning involves using rich-media technologies to enable remote and face-to-face students to jointly participate in the same live classes. This article presents blended synchronous learning designs from seven case studies that were part of a project funded by the Australian Government Office for Learning and Teaching and articulates principles for implementation as espoused by the teachers who enacted them. A wide range of technologies (including video conferencing, web conferencing and virtual worlds), tasks (namely collaborative evaluation, group questioning, class discussion, problem solving and collaborative design) and levels of student interaction (from lightweight to tightly coupled) were present within the designs. The main issues that teachers confronted when facilitating blended synchronous lessons were those relating to communication and those relating to cognitive overload caused by split attention. Key pedagogical principles for enactment as identified by the lead teachers included the need for extensive preparation, clear instructions, composure, flexibility, advance preparation of students and savvy utilisation of support staff.
\end{abstract}

\section{Introduction}

The traditional notions of the on-campus university experience are changing, with many students choosing to participate wholly or partially away from their institutions' campuses (Gosper et al., 2008). The decision by many students to not attend classes or to enrol in online or distance mode is driven by lifestyle demands encompassing intensive and often irregular work, family and social commitments (James, Krause, \& Jennings, 2010). As a result of these changes in attendance patterns and enrolment modes, universities need to find new ways to engage students in learning activities that can be effectively undertaken irrespective of their geographic location. A key challenge is the provision of collaborative learning activities, which are a cornerstone of contemporary social constructivist pedagogical approaches and which are also essential in preparing graduates for the modern workplace (Dillenbourg, 1999; Goodsell, Maher, Tinto, Smith, \& MacGregor, 1992).

To date, remote students have tended to be supported in their learning primarily through asynchronous activities and resources such as recorded lectures, electronic documents, and discussion forums provided within a learning management system (LMS). However, these asynchronous methods may not provide effective support for learning in cases where students need to engage in real-time conversations, where they need to rapidly share audio and visual content, or where presence and community are important elements of the learning episode. The fact that remote students may not be receiving an equivalent education to their on-campus counterparts has been identified as an issue by Australia's Tertiary Education Quality and Standards Agency (TEQSA, 2013).

In this context, learning designs using rich-media real-time communication tools such as video conferencing (both desktop - e.g., Skype - and room based), web conferencing (e.g., Adobe Connect, Blackboard Collaborate, Wimba) and 3D virtual worlds (e.g., Second Life) have become increasingly popular (Bower et al., 2012); their synchronous and multimodal nature can be used to facilitate efficient 
discussion, content exchange and identity representation. (See Bower, Kennedy, Dalgarno, \& Lee, 2011, for a more detailed argument about the potential of rich-media synchronous tools within the problem context.) Moreover, as can be seen in the brief literature review below, some academics are starting to use blended synchronous learning approaches as a means of simultaneously engaging remote and face-to-face students in the same live experience using these rich-media real-time technologies. This provides remote students with the ability to participate in live on-campus classes, thus addressing the equivalence-ofexperience issues identified by TEQSA.

This study examined seven blended synchronous learning designs and the insights of the teachers that enacted them, with the goal of helping to inform and refine blended synchronous learning practices. It is part of an Australian Government Office for Learning and Teaching Innovation and Development project entitled "Blended synchronicity: Uniting on-campus and distributed learners using rich-media real-time collaboration tools". (Please visit the Blended Synchronous Learning website at http://www.blendsync.org/ for further information about the project.)

\section{Research and developments in blended synchronous learning}

Educational researchers propose several benefits of using blended synchronous learning approaches. It enables equity of access for students who are geographically isolated or cannot physically attend classes due to life demands (Norberg, 2012). For instance, blended synchronous learning enables people who cannot be present in person because they are working full time, need to mind children, or are ill to still participate in on-campus learning experiences (Pope, 2010). Irvine (2009; see also Irvine, Code, \& Richards, 2013) frames the argument for what she calls multi-access learning as being one of addressing students' need for flexibility and choice by affording them the ability to select and customise the modality or modalities through which they access classes, regardless of their enrolment mode. Moreover, blended synchronous learning accords with evidence indicating better course and program completion rates for students who partake in synchronous interactions with their teacher and peers rather than relying solely on asynchronous communication (Norberg, 2012; see also Power, 2008; Power \& Vaughan, 2010). It can allow participants to experience an instructor's lesson, ask and answer questions, offer comments in class and generally allow engagement "in a similar manner to on-campus students" (White, Ramirez, Smith, \& Plonowski, 2010, p. 35). Blended synchronous learning has also been used in less structured teaching contexts, such as to promote discussion and cooperative learning in graduate and higher degree research classes (Roseth, Akcaoglu, \& Zellner, 2013; Stewart, Harlow, \& DeBacco, 2011). Blended synchronous learning can be used to create an enhanced sense of community between remote and face-to-face participants (Lidstone \& Shield, 2010).

There is wide variety in the tools and affordances used to facilitate blended synchronous learning. Examples include web conferencing systems like Blackboard Collaborate (Spann, 2012) and Saba Centra (White et al., 2010), virtual worlds like Second Life (Beltrán Sierra, Gutiérrez, \& Garzón-Castro, 2012), chat rooms with video feeds (Lidstone \& Shield, 2010), and even custom-built systems comprised of tools like Etherpad, Google Hangouts, Piazza and online forms (Roseth et al., 2013). The way in which tools are organised and arranged in multimodal clusters impacts upon how they are used. For example, Lidstone and Shield comment that their "postage stamp"-sized video feed of the classroom was used as a "cueing" device to enhance a sense of connectedness for distance students using text chat, as opposed to being used as a transmission device for content and interaction (p. 96).

The performance of the platform in terms of functionality and reliability is similarly critical to the effectiveness of the lesson (White et al., 2010). Lags in audio, for example, can be highly detrimental to the success of blended synchronous learning activities (White et al., 2010). This can lead to teachers choosing low-bandwith tools such as text chat over higher bandwidth options such as audio and video (Lidstone \& Shield, 2010). Capturing appropriate video feeds as the teacher moves around the classroom can also be problematic (White et al., 2010). Care must be taken to ensure that the face-to-face classroom experience is not adversely affected by the technology interfering with normal lesson activities or the teacher being overly distracted (White et al., 2010).

Attempting to teach remote and face-to-face students simultaneously can result in an exponential increase in teaching demands (Norberg, 2012). For this reason, it may be necessary to limit student numbers in order for teachers to effectively manage and support the blended synchronous learning experience (White 
et al., 2010). Student technical skills and familiarity with the communication platform are issues that warrant consideration before attempting to teach using blended synchronous learning approaches (White et al., 2010).

The use of a teaching assistant is often critical to the success of blended synchronous learning experiences, because they can attend to technology-related problems and other issues not related to the core aspects of the lesson (White et al., 2010). It has been suggested that increasing the ratio of teaching assistants to participants may be necessary to minimise disruptions to lessons (White et al., 2010). Having multiple teachers involved in class discussions can also lead to a richer learning experience for students (Lidstone \& Shield, 2010).

To date, there have not been any collective case studies of blended synchronous learning documented in the literature that can be used as a basis to understand how to enhance practice in this area.

\section{Method}

Case study partners were selected from 1,748 responses to a 2011-2012 survey of Australian and New Zealand educators on their use of rich-media synchronous technologies (see Bower et al., 2012). Criteria for selection of case study partners included: (a) whether they were synchronously uniting face-to-face and remote students using rich media technologies, (b) the extent to which the case involved high-quality pedagogical practices, and (c) the maturity of the design in terms of number of implementations. Cases were also selected so as to represent a range of technologies and discipline areas. Discussions were held with potential case study partners to determine appropriateness for inclusion in the project and willingness to participate. This resulted in the selection of seven case study partners. Prior to the case study observations, the project team worked with the case study partners to reflect upon and in some cases refine the pedagogical and technological aspects of the blended synchronous learning designs. However, it is important to note that the extent to which designs were adjusted was always at the discretion of the case study partners.

Sources of data collected from each case study as part of the project included: (a) a pre-observation teacher-documented overview of the case as it had been implemented in the past, (b) pre-observation teacher interviews in order to determine the rationale for the designs as well as teachers' insights into the blended synchronous learning approach, (c) video and screen recording of the blended synchronous learning lessons, (d) researcher observations of the lessons, (e) post-observation student survey responses, (f) post-observation student focus group interviews, and (g) post-observation teacher interviews. The summary of each of the designs was derived from the pre-observation teacher-documented overviews, the researcher observations of the lessons, and the video and screen recordings of the blended synchronous learning lessons. The project team worked collectively to compose the lesson summaries and used the multiple data sources to triangulate and cross-validate the accuracy of descriptions.

The examination of teacher perceptions of blended synchronous learning issues and principles was based upon teacher responses to the pre-observation interview questions that focused on blended synchronous learning problems as well as the key strategies that they employ. Pertinent aspects of the transcribed teacher pre-interviews were extracted and then classified using an open-coding phase to determine preliminary analytic categories. Next, axial coding was carried out to determine emergent themes and refine categorisations. Lastly, a selective-coding phase supported representation of the conceptual coding categories for reporting purposes. (See Neuman, 2006, for further details on this approach.) The blended synchronous learning designs are described below, followed by an explication of pedagogical issues and strategies espoused by the teachers.

\section{Blended synchronous learning designs}

\section{Learning design \#1: Web conferencing to develop investment understanding (collaborative evaluation task)}

In this learning design, a small team of academics from the Department of Applied Finance and Actuarial Studies at Macquarie University attempted a collaborative evaluation activity using the Adobe Connect web conferencing system (see Figures 1 and 2). After the teacher briefly introduced the task, remote and 
face-to-face students were randomly grouped into two breakout rooms, where they had to evaluate the written responses of two past students to an examination question. The students negotiated marks using text chat and summarised findings about examination technique in a notes pod. Remote and face-to-face students were randomly grouped together, which meant that students in the face-to-face classroom did not necessarily have the opportunity to talk with one another. However, using the web conferencing system in this way levelled the playing field for participants across both modes. A lack of understanding of how to operate the technology temporarily interfered with students' ability to undertake the exercise. A teaching aide provided substantial operational assistance to ensure that remote students were receiving all teacher communications and were able to contribute to discussions. The teacher (with the assistance of the teaching aide) was then able to share groups' findings and discuss them with the class. The blended synchronous learning design enabled remote and face-to-face students to successfully complete the collaborative evaluation activity together.

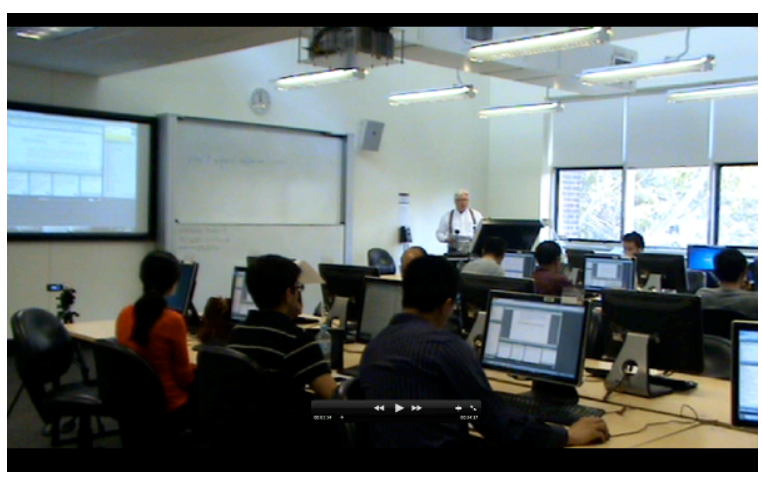

Figure 1. Face-to-face classroom setup

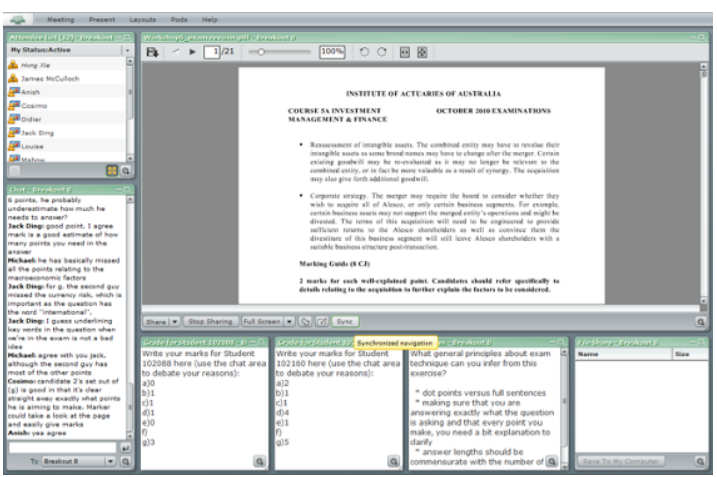

Figure 2. Remote student view

\section{Learning design \#2: Room-based video conferencing to develop understanding of healthcare quality improvement approaches (collaborative evaluation task)}

Access Grid room-based video conferencing was used to bring together students on three campuses of the University of Western Sydney in this learning design (see Figures 3 and 4). The lesson, in the discipline of health informatics, involved a combination of a lecture and a small-group activity with a report back to the whole group. As well as the lecturer and tutor present at one site, there was also a tutor present at one of the other two sites. The Access Grid setup involved the use of multiple screens showing students at each site and the teachers, plus an additional area for showing presentation slides. During the report-back phase of the lesson, students made use of an interactive whiteboard to share diagrams with classmates at the other sites. The lesson proceeded smoothly, with students at all of the campuses able to participate effectively. Although student questionnaire and focus group responses were generally positive, some students nevertheless indicated a preference for face-to-face classes. Some issues that students identified included an inability to hear the questions asked by students at remote sites and difficulty in making out the details of the material shared through the interactive whiteboard. The effectiveness of the strategies used by the lecturer to involve students on other campuses was highlighted in student feedback, and the role of the remote tutor in encouraging input from remote students emerged as an important element of the lesson.

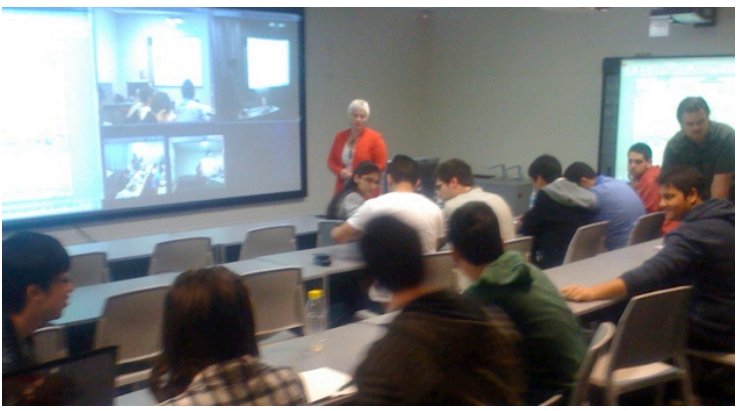

Figure 3. Face-to-face classroom setup

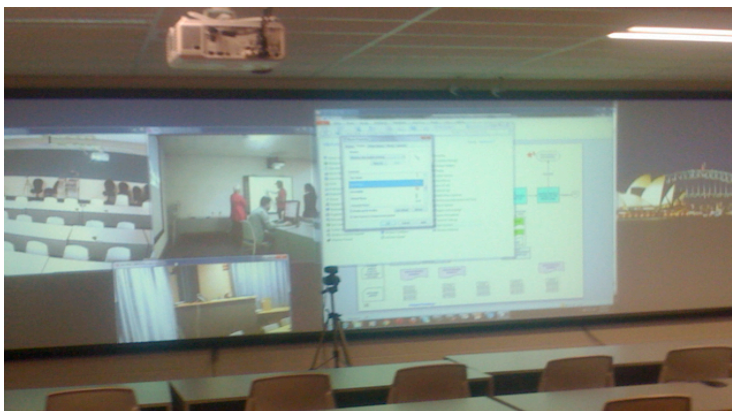

Figure 4. Remote classroom view 


\section{Learning design \#3: Web conferencing to develop microscopic tissue analysis and interpretation skills (group questioning)}

This learning design used Adobe Connect to bring together on-campus students in a computer laboratory at Charles Sturt University, Wagga Wagga and distance education students participating from off-campus locations to perform an interactive review of medical science (histology) material for an upcoming exam (see Figures 5 and 6). During the first part of the lesson, the teacher, wearing a microphone to allow her speech to be audible to remote students through Connect, presented a series of multiple-choice and shortanswer questions. Students (both on-campus and remote) answered the questions using the built-in response tools. Summaries of student responses were presented graphically, with the teacher explaining why each answer was correct or incorrect. Students asked clarifying questions either verbally (on-campus students) or using text chat (remote students). During the second part of the lesson, students were grouped in pairs and asked to complete tissue image identification and labelling tasks in breakout rooms within Connect. Group members reported back on the task, and the teacher supplied feedback and clarification. During the first of those tasks, on-campus students were grouped with on-campus students and remote with remote, whereas during the second task, on-campus students were grouped with remote students. Communication between on-campus students was noticeably smoother than that between remote students, with the absence of an audio channel apparently making it difficult to coordinate the labelling task for some groups. The whole-group aspects of the lesson (questions at the beginning and reports back at the end) proceeded smoothly, with the teacher able to effectively monitor the face-to-face classroom and web conferencing environment and respond to questions and comments from students in both modalities.

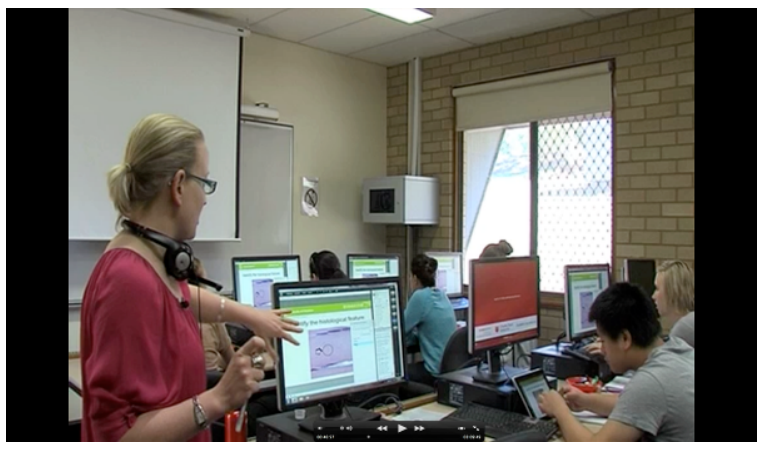

Figure 5. Face-to-face classroom setup

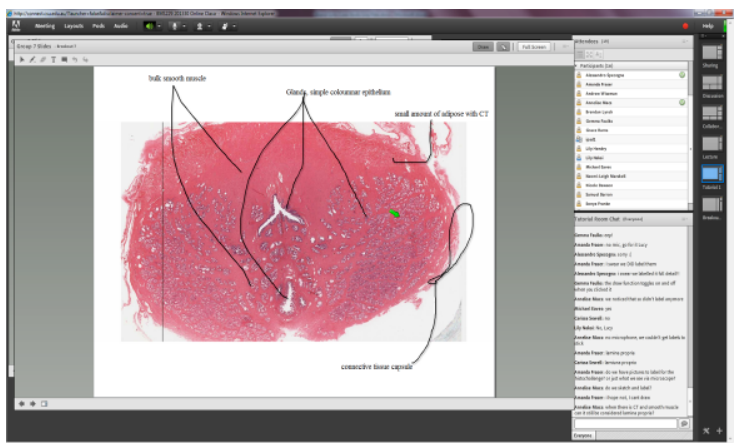

Figure 6. Remote student view

\section{Learning design \#4: Web conferencing for participation in statistics tutorials (collaborative problem solving)}

This design used the Blackboard Collaborate web conferencing system to enable remote students to participate in introductory statistics tutorials that were being held at Southern Cross University's Gold Coast campus (see Figures 7 and 8). The teacher logged into the Collaborate session via her tablet computer so that she could write on the slides in the web conferencing environment. The screen was projected at the front of the face-to-face classroom so that students who were physically present could see the visual material as well as the list of participants who were attending remotely. The teacher then presented a series of slides that led students through the logic of hypothesis testing, annotating the slides to model problem-solving processes. The demonstration included how to select the correct statistical test from a decision chart, how to look up $p$-values from a table of critical values, and how to run statistical tests using a spreadsheet package. The teacher regularly asked both face-to-face as well as remote students whether or not they understood and gave them ample opportunities to ask questions. She then provided time for students to solve problems of their own. Face-to-face students worked individually, in pairs or in larger groups, while remote students worked in breakout rooms using text chat. The teacher sporadically repeated spoken conversation from the face-to-face classroom into the lectern microphone so that remote students could acquire a sense of the on-campus discussion. Although the face-to-face students did not have direct interaction with the remote students, the blended synchronous learning design appeared to support both cohorts in achieving the intended learning outcomes. 


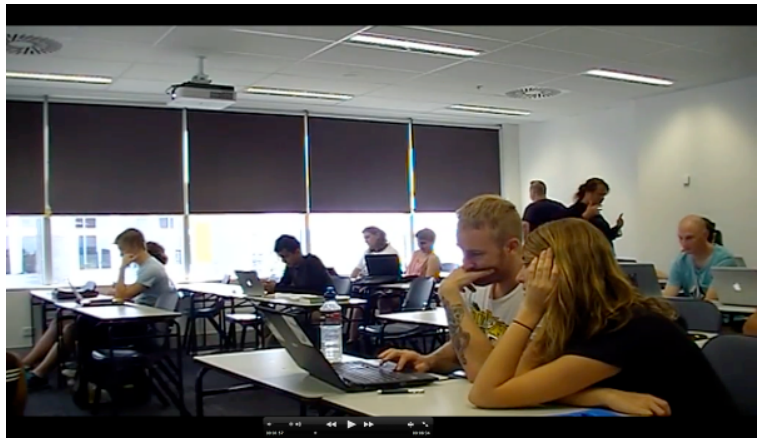

Figure 7. Face-to-face room setup

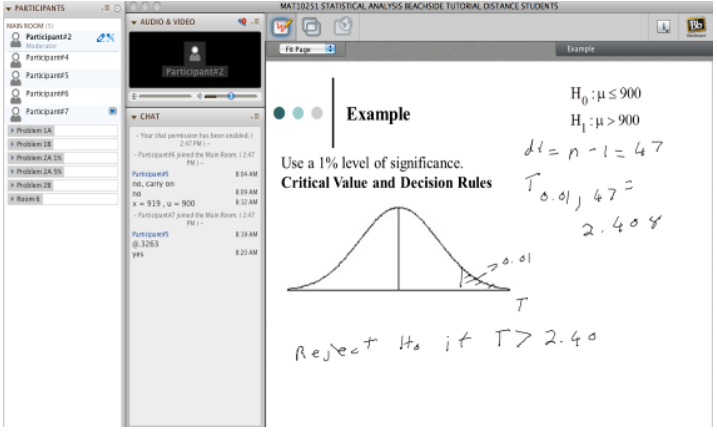

Figure 8. Remote student view

\section{Learning design \#5: Virtual worlds to facilitate Chinese language learning (paired role- play)}

In this design, students enrolled in an introductory Chinese unit at Monash University participated in a tightly constructed role-play activity within the virtual world of Second Life (see Figures 9 and 10). The activity was based on themes appearing in the set textbook for the unit, and it sought to develop participants' Mandarin language communicative capabilities. Students could choose to participate in oncampus computer laboratories or from external locations. At the time of the tutorial, students logged in to Second Life and were allocated into groups of two by the teacher, who was both in the physical classroom and in-world. The objective of the lesson was for students to make a bowl of soup dumplings in the kitchen of a restaurant within the virtual world. This required them to utilise a range of previously learnt vocabulary, phrases and sentence patterns to ask the non-player character (NPC) hostess of the restaurant what ingredients they needed, where they could buy those ingredients, and how to get there. They then had to follow the hostess' directions to get to a traditional farmers' market and purchase the ingredients from another NPC selling fruit, vegetables and meat. Finally, they had to take the ingredients back to the restaurant kitchen and cook them on one of the stoves. Remote students were paired with face-to-face students, with communication among the students taking place via voice and text (largely in English) and interaction between the students and the NPCs occurring via Chinese character text chat. Because the task and environment were so extensively designed, the teacher did not need to provide much in-class instruction; he was instead able to spend the majority of the lesson time assisting individual students on a one-to-one basis. Although initially communication between some student pairs was slow to take off, through subsequent close collaboration most pairs were eventually able to obtain the information they needed by conversing with the NPCs and to navigate the environment to complete the various stages of the assigned task.

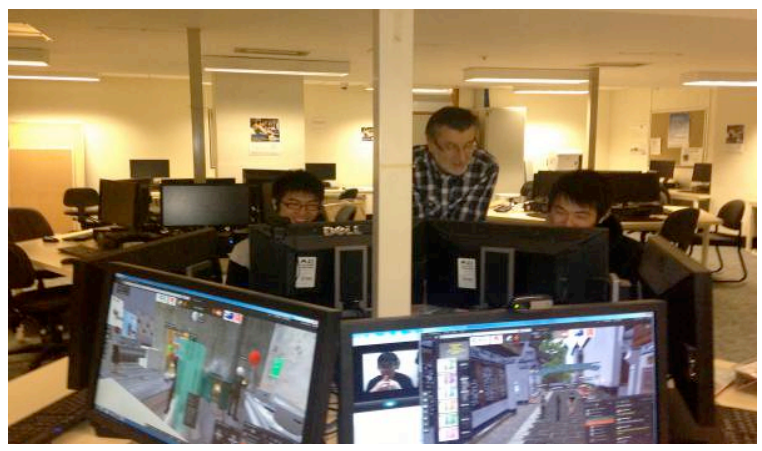

Figure 9. Face-to-face room setup

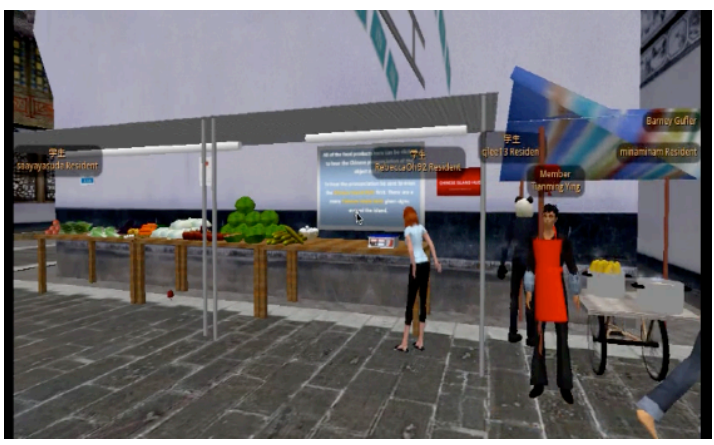

Figure 10. Remote student view 


\section{Learning design \#6: Web conferencing to enable presence in sexology (lecture discussions)}

This learning design, implemented at Curtin University, involved the teacher holding an interactive lecture discussion with sexology students over two hours using the Blackboard Collaborate web conferencing system (see Figures 11 and 12). The content matter of sexology (including sexual function, dysfunction, pleasure and emotions) is often confronting for students, requiring them to concurrently draw upon and distance themselves from their personal experience. In this context, web conferencing was used to engender more embodied presence and participation of remote students in the face-to-face lectures. The teacher presented material but frequently opened up discussion to engage the students in making links to the readings, describing their experiences and sharing their views. On-campus student comments could be heard through the web conferencing system, and remote students contributed to the discussion using text chat. Students in the face-to-face classroom could also add to the text discussion thread using teacher-supplied iPads. Activities - for instance, a whiteboard graphing activity and a vignette/case analysis problem discussion - were included to increase the level of student involvement. The teacher, through the blended synchronous environment, played a crucial role in fostering a safe, open atmosphere that encouraged and inspired everyone to actively take part.

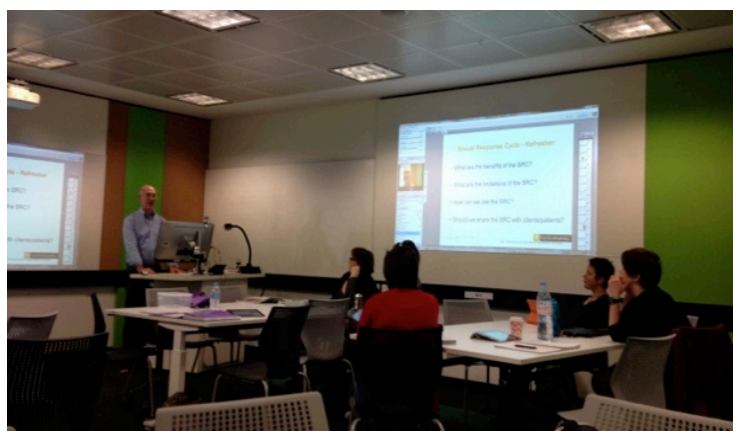

Figure 11. Face-to-face room setup

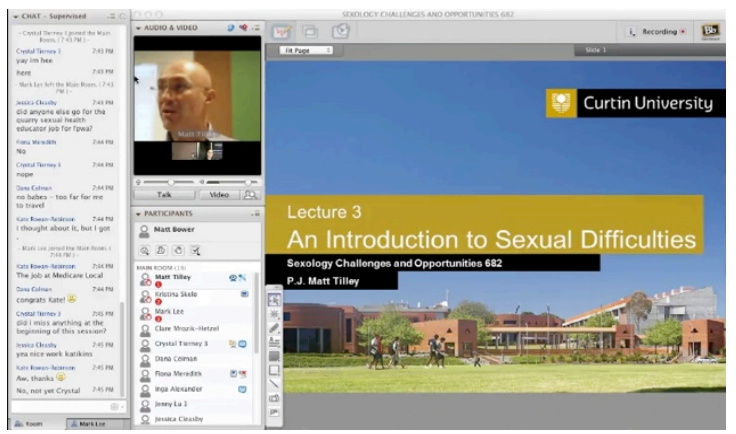

Figure 12. Remote student view

\section{Learning design \#7: Virtual worlds for teacher education (collaborative evaluation and design)}

The AvayaLive Engage virtual world platform was used to create a blended reality (Bower, Cram, \& Groom, 2010) learning environment in this design. Students in the face-to-face classroom could see and hear remote students' avatars via a projection of the virtual world, and remote students could see and hear their face-to-face peers via a video stream into the virtual environment (see Figures 13 and 14). The approach was used in a second-year educational technology unit for pre-service teachers offered by Macquarie University, to help the pre-service teachers develop an understanding of how virtual worlds could be used to enable new forms of interaction and participation. The lesson incorporated teacher presentations, whole-class discussions in which students indicated their perceptions about the utility of virtual world technology, as well as group-based brainstorming and design activities about the possible applications of the technology in education. At times students were asked to represent their preferences by means of their physical placement in the virtual and face-to-face classrooms. Group work was attempted in separate breakout areas in both spaces, with face-to-face and remote group work notes shared on separate surfaces within the virtual world classroom. Network and system issues affected the quality of the student experience. However, the trial nonetheless served to demonstrate and provide proof of concept that blended reality classes are a feasible learning and teaching strategy for uniting remote and face-to-face students. 


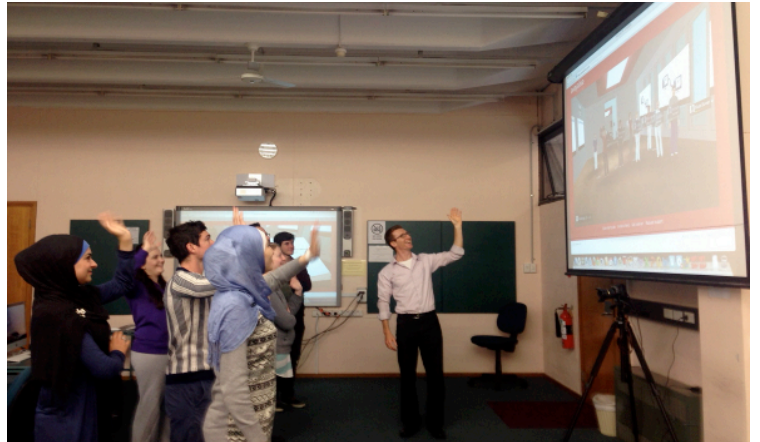

Figure 13. Face-to-face room setup

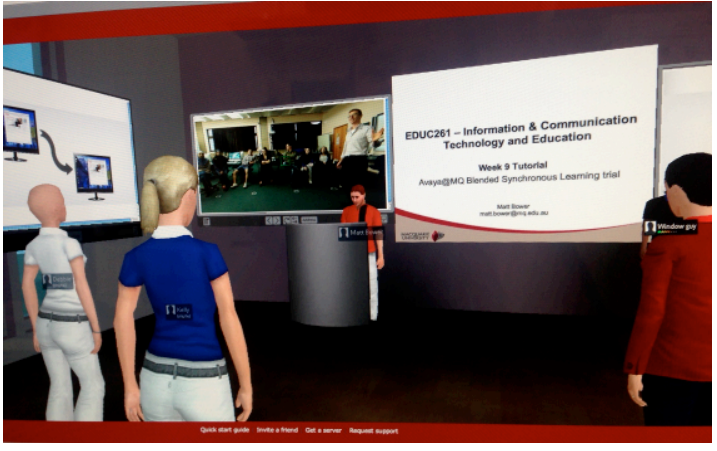

Figure 14. Remote student view

\section{Blended synchronous learning issues and strategies}

\section{Issues}

Many of the concerns that teachers identified regarding blended synchronous learning related to communication. For instance, they reported having to "constantly check that the remote audience is getting the required information", and if students were using audio then there was a need to "manage turn taking somehow". Additionally, capturing the teacher's voice posed a problem, especially as he/she moved around the room: "physically being near enough to a microphone to be able to actually talk to ... students that are in the virtual environment at the same time that I'm talking to the students in the physical environment has been difficult". According to one of the teachers, capturing audio discussions in the faceto-face classroom without specialised equipment was also problematic:

One of the things that is a challenge is where the cameras face and where you physically stand and face. There have been times when having to repeat questions [sic] because those online can't hear the questions from a class, so the mike's probably not powerful enough.

If a virtual world was being used to facilitate this blended synchronous learning, then the audio communication issues could be duplicated in-world because "it is also a spatial environment; if a student moves away from the space where you have your avatar, then they're not going to hear anything you say, so you have to also at the same time be able to move the avatar". Teachers also saw the performance of the underlying technology as a crucial factor - for instance, when the technology fails. The remote students' computer systems and Internet connections were seen to have a critical impact on the experience for those students.

Teachers felt it was particularly challenging to maintain simultaneous awareness of both groups of students. One teacher expressed how it meant being conscious of a dual-student view: "you need to constantly be aware of how you are appearing to students in the face-to-face classroom and also the virtual world". Part of the challenge is that this was occurring in a complex environment, demanding that teachers constantly make multiple decisions: "you've got a lot of stuff going on in the background that you either choose to ignore or that you respond to". While it was seen as difficult to determine the perceptions of two cohorts of students, it was also seen as essential to respond to student needs: "if you are not cognisant of that and you don't reflect on how the students are reacting to you ... then you won't recognise that those changes in style are required". Discerning the perceptions of both cohorts of students was seen as particularly challenging in a blended synchronous setting because remote student perceptions were not as easily gauged as those in the face-to-face class. In addition, adequately recording sessions was thought to be an important issue, since neither online nor lecture-recording systems would necessarily capture all of the blended synchronous learning discourse and interactions that transpired.

\section{Strategies}

Most of the teachers discussed at length the heightened need to be well prepared for blended synchronous lessons ("I would say preparation is key ... making sure that you do have everything you need preloaded, well organised before the class starts"). For instance, teachers would "put everything on the LMS 
beforehand so students have a copy to browse" and "set up breakout rooms with the questions, etc". One teacher observed that the amount of preparation was greater than if teaching purely online or purely faceto-face: "having things set up I think is the heart of it ... so it definitely would be easier to do one or the other".

Part of that preparation involved ensuring that "instructions about what to do and how to do it are clear and premeditated, because [in a blended synchronous scenario] it's easy for students not to know". One teacher placed instructions in written form on the LMS before the lesson so that both remote and face-toface students could access them in advance. One teacher recommended "pairing remote students with another student in the physical classroom and then making it clear to the person in the physical classroom that they are a conduit of communication if the student in the virtual environment has an issue". This reduced the dependency (and load) upon the teacher in terms of ensuring remote students understood what they were supposed to be doing as well as troubleshoot any technical issues.

Teacher direction was seen as crucial to encouraging participation across multiple sites: "you really have to prompt quite strongly to get the campuses that you are not physically attending to get a response ... I might say, 'Penrith, this question is for you' or 'Campbelltown, now it is your turn'”. Further, explicit direction was recommended to optimise student approaches to operating within the blended synchronous environment - for instance, "encouraging students to have iLearn [LMS] and Adobe Connect open at the same time" and asking them to "use the prefix 'Q' for chat contributions to distinguish questions requiring responses from comments [not requiring responses]".

Four of the seven teachers expressed the desirability or indeed need for at least one support teacher: "so the ideal situation probably is where you have two instructors, one who is present in the virtual environment and one who is in the physical environment to ensure that the communication is flowing well through both environments". Others suggested that the support role could include "helping students who might have a problem with the audio" and "keeping an eye on incoming questions". Teachers also identified that the amount of assistance required was dependent on the size of the class - for instance, that a class of 60 students might require two assistants.

Ability to maintain composure was seen as a critical teacher attribute: "When you have technical problems, you can't lose your lolly; instead, you have to think: How long will it be down? What is the cost-benefit of waiting?" The ability to rapidly make decisions about courses of action was emphasised by another teacher:

If a student's computer goes offline or whatever - there's some hitch at their end where they're temporarily unable to continue, to not participate in the class - how are you going to handle that? If they're able to get back online quickly then probably it's not a big issue. If it takes them 10 or 15 minutes to get back online then it becomes a big issue because you can't make the rest of the class wait around ... so you need to have something in the back of your mind as to how you're going to deal with that so that student gets the same learning experience, the same access as the ones that are in the physical classroom.

Teachers also expressed the need to prepare students for the blended synchronous learning experience by "clearly announcing to the students that this is what your computer will need, this is what you'll need to be able to access this, and for the first session, just giving them a chance to play with things and get comfortable before it becomes a bit more high stakes, I guess, with regard to the interactivity". One teacher identified how part of this preparation involved the management of expectations: "Students need to become aware that they won't have physical contact with a lecturer". Some teachers used orientation activities aimed at equipping students with prerequisite technical capabilities. One organised a virtual treasure hunt as such an activity, designed to assist students in gaining the required familiarity with the virtual world. Another teacher recommended scheduling the session to commence 10 minutes early to allow time for the remote students to test their systems.

In order to address the challenge of communicating with two cohorts of students at once, one teacher pointed out that it was important to ensure "your body is positioned so that it's in an open and available position for both remote and face-to-face students". Clear audio involved talking at a "measured pace that means that your audio is being received by students that are remote ... but also not too slow for students in 
the classroom". Logging in as a student on a second computer was also identified as a strategy to appreciate the remote student view.

While there was no definitive strategy for broaching the split attention caused by catering to two cohorts of students at the same time, one teacher's comments intimated that the solution may lie in designing the learning environment so that the focus of activity is self-evident: "If you want to say where is the focus of student attention during the lesson, the focus of student attention during the lesson is very definitely in the virtual environment." If all students are immersed in a single environment, then communicative difficulties imposed by attempting to synchronously blend remote and face-to-face participants may be reduced or even eliminated.

\section{Discussion and conclusion}

The blended synchronous learning designs above demonstrate the range of subject areas and task types that can be supported using rich-media synchronous technologies. Collaborative evaluation, group questioning, collaborative problem solving, role-play, whole-class discussions and collaborative design tasks could all be enacted. Finance, health informatics, biology, statistics, language, sexology and teacher education content could all be represented. A wide range of technologies could also be used, including video conferencing, web conferencing and virtual worlds. In each case, the technological setup and capabilities of the teacher were critical to the success of the blended synchronous lessons and activities.

The main issues identified by teachers regarding the simultaneous teaching of remote and face-to-face students were communication problems (capturing and managing audio discussions) and cognitive load caused by the demands of teaching two cohorts of students at once (having to maintain awareness of the remote and face-to-face student view, operating the collaborative technology, troubleshooting technical issues for remote students, monitoring the reactions/discerning the perceptions of both cohorts). These align with and expand upon problems identified by other researchers (Norberg, 2012; White et al., 2010).

The teachers alluded to several strategies that could be used to alleviate or reduce the impact of these issues, including advance organisation of resources, clear and explicit instructions to students, using faceto-face students to relay communication to remote students, utilising workarounds when systems fail, and having a focused environment in which to conduct collaborative activity. They felt there was a heightened need to prepare remote students for the blended synchronous learning classes in terms of their technological setup, technological skills, and expectations. The majority of teachers believed having a teaching assistant was highly advantageous in helping to deal with the increased cognitive load required to manage blended synchronous learning classes (aligning with recommendations by Lidstone \& Shield, 2010, and White et al., 2010).

This article has provided only an overview of the designs and reflections of teachers across the seven case studies. Future publications will report in depth on the findings of each case as enacted, taking into account analysis of student data. Furthermore, a cross-case analysis of lessons and student perceptions is being prepared in an effort to understand the influence of different design elements and strategies. Preliminary results indicate that the way in which the technology is used determines the extent to which students perceive a sense of co-presence and of communication and sharing occurring between remote and on-campus participants, but that it is the task design and pedagogy that influence the depth of learning.

As technology and bandwidth continue to improve, we may be entering an age of ubiquitous participation, where remote participants may be represented in any classroom via video modelling and mixed/augmented reality as though they were actually in the room. Until that time, teachers will need to leverage the potentials of the available rich-media technologies to unite remote and face-to-face students, employing appropriate strategies in an attempt to mitigate or overcome the constraints. This research provides an evidential basis for designing and optimising such blended synchronous learning tasks and experiences. 


\section{Acknowledgements}

Extensive thanks go out to our case study partners (in order of presentation of the case studies in this article):

- James McCulloch, Timothy Kyng, David Pitt and Hong Xie (Macquarie University);

- Joanne Curry (University of Western Sydney);

- $\quad$ Lucy Webster (Charles Sturt University);

- $\quad$ Nicola Jayne (Southern Cross University);

- $\quad$ Scott Grant (Monash University);

- $\quad$ Matt Tilley (Curtin University);

- Matt Bower (Macquarie University).

Funding for this project has been provided by the Australian Government Office for Learning and Teaching (OLT). The views expressed in this article do not necessarily reflect the views of OLT.

\section{References}

Beltrán Sierra, L. M., Gutiérrez, R. S., \& Garzón-Castro, C. L. (2012). Second Life as a support element for learning electronic related subjects: A real case. Computers \& Education, 58, 291-302.

Bower, M., Cram, A., \& Groom, D. (2010). Blended reality: Issues and potentials in combining virtual worlds and face-to-face classes. In C. H. Steel, M. J. Keppell, P. Gerbic, \& S. Housego (Eds.), Curriculum, technology \& transformation for an unknown future. Proceedings ascilite Sydney 2010 (pp. 129-140). Brisbane, Australia.

Bower, M., Kennedy, G. E., Dalgarno, B., \& Lee, M. J. W. (2011). Uniting on-campus and distributed learners through media-rich synchronous tools: A national project. In G. Williams, N. Brown, M. Pittard, \& B. Cleland (Eds.), Changing demands, changing directions. Proceedings ascilite Hobart 2011 (pp. 150-155). Hobart, Australia.

Bower, M., Kennedy, G. E., Dalgarno, B., Lee, M. J. W., Kenney, J., \& de Barba, P. (2012). Use of media-rich real-time collaboration tools for learning and teaching in Australian and New Zealand universities. In M. Brown, M. Hartnett, \& T. Stewart (Eds.), Future challenges, sustainable futures. Proceedings ascilite Wellington 2012. Wellington, New Zealand.

Dillenbourg, P. (Ed.). (1999). Collaborative learning: Cognitive and computational approaches. New York, NY: Elsevier.

Goodsell, A. S., Maher, M. R., Tinto, V., Smith, B. L., \& MacGregor, J. T. (Eds.). (1992). Collaborative learning: A sourcebook for higher education. University Park, PA: National Center on Postsecondary Teaching, Learning, and Assessment.

Gosper, M., Green, D., McNeill, M., Phillips, R., Preston, G., \& Woo, K. (2008). The impact of webbased lecture technologies on current and future practices in learning and teaching [Final project report]. Australian Learning and Teaching Council. Sydney, Australia.

Irvine, V. (2009). The emergence of choice in 'multi-access' learning environments: Transferring locus of control of course access to the learner. In G. Siemens \& C. Fulford (Eds.), Proceedings of World Conference on Educational Multimedia, Hypermedia and Telecommunications 2009 (pp. 746-752). Chesapeake, VA: Association for the Advancement of Computing in Education.

Irvine, V., Code, J., \& Richards, L. (2013). Realigning higher education for the 21 st-century learner through multi-access learning. MERLOT Journal of Online Learning and Teaching, 9(2), 172-186.

James, R., Krause, K., \& Jennings, C. (2010). The first year experience in Australian universities: Findings from 1994 to 2009. Centre for the Study of Higher Education. Melbourne, Australia.

Lidstone, J., \& Shield, P. (2010). Virtual reality or virtually real: Blended teaching and learning in a Master's level research methods class. In Y. Inoue (Ed.), Cases on online and blended learning technologies in higher education: Concepts and practices (pp. 91-111). Hershey, PA: Information Science Reference.

Neuman, W. L. (2006). Social research methods: Qualitative and quantitative approaches (6th ed.). Boston, MA: Pearson.

Norberg, A. (2012). Blended learning and new education logistics in Northern Sweden. In D. G. Oblinger (Ed.), Game changers: Education and information technologies (pp. 327-330). Boulder, CO: EDUCAUSE. 
Pope, C. (2010, September). Breaking down barriers: Providing flexible participation options for oncampus courses. Paper presented at the Fifth Education Research Group of Adelaide (ERGA) Conference, Adelaide, Australia.

Power, M. (2008). The emergence of a blended online learning environment. MERLOT Journal of Online Learning and Teaching, 4(4), 513-514.

Power, M., \& Vaughan, N. (2010). Redesigning online learning for international graduate seminar delivery. The Journal of Distance Education, 24(2), 19-38.

Roseth, C., Akcaoglu, M., \& Zellner, A. (2013). Blending synchronous face-to-face and computersupported cooperative learning in a hybrid doctoral seminar. TechTrends, 57(3), 54-59.

Spann, D. (2012). Five innovative ways to use virtual classrooms in higher education. In M. Brown, M. Hartnett, \& T. Stewart (Eds.), Future challenges, sustainable futures. Proceedings ascilite Wellington 2012. Wellington, New Zealand.

Stewart, A. R., Harlow, D. B., \& DeBacco, K. (2011). Students' experience of synchronous learning in distributed environments. Distance Education, 32, 357-381.

Tertiary Education Quality and Standards Agency. (2013). TEQSA and the Australian Qualifications Framework: Questions and answers.

White, C. P., Ramirez, R., Smith, J. G., \& Plonowski, L. (2010). Simultaneous delivery of a face-to-face course to on-campus and remote off-campus students. TechTrends, 54(4), 34-40.

This article is a revised and updated version of a paper that received the Best Full Paper Award at ascilite Sydney 2013, gaining the additional recognition of publication in AJET. The reference for the conference version is:

Bower, M., Kenney, J., Dalgarno, B., Lee, M. J. W., \& Kennedy, G. E. (2013). Blended synchronous learning: Patterns and principles for simultaneously engaging co-located and distributed learners. In H. Carter, M. Gosper, \& J. Hedberg (Eds.), Electric dreams.

Proceedings ascilite Sydney 2013 (pp. 92-102). Sydney, Australia: Macquarie University. Retrieved from

http://www.ascilite.org.au/conferences/sydney13/program/papers/Bower.pdf

Corresponding author: Matt Bower, matt.bower@mq.edu.au

Australasian Journal of Educational Technology (C) 2014.

Please cite as: Bower, M., Kenney, J., Dalgarno, B., Lee, M. J. W., \& Kennedy, G. E. (2014). Patterns and principles for blended synchronous learning: Engaging remote and face-to-face learners in rich-media real-time collaborative activities. Australasian Journal of Educational Technology, 30(3), 261-272. 